\title{
EVALUATING POLICY INTERVENTIONS FOR DELAYED DISCHARGE: A SYSTEM DYNAMICS APPROACH
}

\author{
Wael Rashwan \\ Mohamed Ragab \\ Waleed Abo-Hamad \\ Amr Arisha \\ 3S Group, College of Business \\ Dublin Institute of Technology \\ Dublin 2, IRELAND
}

\begin{abstract}
Global population ageing is creating an immense pressure on hospitals to meet the growing demand for elderly healthcare services. Current demand-supply gaps results in prolonged waiting times for patients and substantial costs for hospitals due to delay in discharges. This paper uses System Dynamics (SD) methodology to map the dynamic flow of elderly patients in the Irish healthcare system. The developed system dynamic model helped decision makers to envisage the complexity resulted in the system due to the infringing parameters. Stock and flow intervention policies are proposed and evaluated subject to the projected future demographic changes. The model enables policy makers to identify potential strategic policies that will contribute significantly to overcome the delayed discharge for elderly patients. Future work will focus on using a modified model of the developed national model in order to assist local communities in Ireland in their long-term planning for non-acute service sector for elderly.
\end{abstract}

\section{INTRODUCTION}

There are more aging people living on earth more than ever before - an indicator of advanced global health systems (McDermid and Bagshaw 2011). Worldwide, there are around 600 million persons aged 65 years and over; this total will double by 2025 and will reach virtually two billion by 2050 (WHO 2011). In Europe, there are currently 108 million elderly people who constitute $15 \%$ of the continent's population. This figure is expected to reach $26 \%$ by 2050 (Piers et al. 2011). In Ireland, the elderly population is projected to grow from 0.5 to 1.3 million over the next 30 years (Connell and Pringle 2004). As societies age and the cost of providing health and social care rises, innovative approaches to the delivery of services are becoming increasingly important. Discrete-Event Simulation (DES) has been proven to be an effective and flexible tool for modeling processes in such stochastic complex environments (Eldabi et al. 2006). Healthcare managers apply DES for assessing current performance, predicting the impact of operational changes, and examining the tradeoffs between system variables (Litvak et al. 2008; Thorwarth et al. 2009; Abo-Hamad et al. 2012; Abo-Hamad and Arisha 2013).

This paper describes a national project carried out within Health Service Executive (HSE). The aim of the project is to find solutions that help to overcome the delayed discharge of elderly patients whilst meeting the growing demand over the next five years. The first phase of this project began in 2012 where a DES model was developed to model the flow of elderly patients (Ragab et al. 2012). Although using DES approach was found to be effective for understanding the system constraints, several problems aroused while trying to define the source of the problems. Data Problems varied between irrelevant, insufficient, and/or accuracy issues. DES models tend to define the demand as static variable, however this is believed to adversely affect the outcomes credibility of proposed strategies. In an attempt to overcome aforementioned challenges, System Dynamics (SD) approach was recommended. SD provides 
a wider system thinking that is more effective for modeling large and complex systems which characterized by undefined boundaries (Brailsford 2008). Healthcare systems often have many different stakeholders e.g. health providers and funders where actions and activities at one part of the healthcare system often result in unexpected and unwanted consequences elsewhere. SD is a well-received approach for modeling strategic aspects of policy and national issues such as patient flow in emergency care systems and planning for elderly care (Wolstenholme 1993 and 1999; Walker and Haslett 1999; Desai et al. 2008).

The primary aim of this study is to deliver a holistic and strategic capacity-planning model at the national level. This model is believed to support policy makers in their process to take decisions that are well assessed and have less risk on elderly patients. It is also envisaged to have a positive impact on the delayed discharge issue.

\section{BACKGROUND}

In spite of rapid increase in total healthcare expenditure in the 2000s, Ireland still had modest primary and community health services, with two thirds of the population paying the full out-of-pocket cost of primary care, and a model of care that favored hospitals over community services (WHO 2012). Shortage of community care beds leads to delayed discharges from acute hospitals. As a result, new admissions into hospitals are restricted and hospitals have to carry unjustified costs. Acute beds are considered among the most expensive resources of the entire healthcare system (Liotta et al. 2011). Consequently, many elderly and dependent patients who have finished their hospital treatment are being forced to remain in hospital beds for over six months as an alternative care due to the unavailable alternatives (Department of Health 2012a). Delayed discharge is defined as patients who have completed the acute phase of their care and are medically fit for discharge. The high number of delayed discharges means that beds cannot be vacated to treat new patients, thereby more buildup in the queues for hospital ED trolley and treatment lists. An analysis by the HSE shows that there are 700 patients on average monthly, are awaiting 'step-down' facilities to be discharged from hospitals. The cost of running an acute bed is about $€ 850$ at a night and the cost of caring 700 delayed patients costs about $€ 595,000$ daily.. In an analysis of the reasons for the delay in discharging, it was found that $75 \%$ of those patients were seeking nursing home care, $90 \%$ of these patients are 65+. Further complications associated with delayed discharges of patients can adversely affect acute hospitals' ability to cut their waiting lists and deliver their services efficiently and effectively (Majeed et al. 2012).

\section{MODEL CONCEPTUALIZATION AND FORMULATION}

System Dynamics (SD) was developed at the end of the 1950s and the beginning of the 1960s at the Massachusetts Institute of Technology's Sloan School of Management by Professor Jay Forrester. He employed the engineering feedback control principles and techniques to management and social science and then applied to any type of complex systems that exhibit dynamic behavior over time. The system dynamics approach seeks to support the decision-making processes that should lead to the improvement of the system, besides it can be very effective in improving the learning in complex systems (Sterman 2000). The growing trend of the SD publications in healthcare advocates this point. Traditionally, discrete-event simulation (DES) models have been applied to deal with details, processes, decision rules, queues and scheduling activities at both operational and tactical levels. DES models require a large amount of quantitative numerical data, and their intrinsic stochastic nature means they require extensive statistical analysis and design of experiments (Xiao et al. 2012). On the other hand, SD's data requirements are different as the focus is usually on the strategic and tactical data. SD models are concerned with the complexity of the system due to the dynamics between different entities and also the causes of certain behaviours in the system. Hence, it is more applicable for the strategic modeling than DES (Brailsford and Hilton 2001). SD Models can also capture and model qualitative data which often required in Healthcare applications. SD models experiments tend to run in a considerable time and can also run interactively in real-time (Brailsford and Hilton 2001; Brailsford 2008). 


\subsection{Conceptualization of Elderly Care Pathways}

Elderly patients are usually defined as those who are aged 65 and older and this study adheres to that convention (Paul and Hariharan 2007). The most challenging of elderly patients are those referred to as frail patients. Frail patients suffer from an array of medical conditions that individually may be curable, but collectively create complex and potentially overwhelming burden of disease (McDermid and Bagshaw 2011). Frail patients constitute $18-20 \%$ of the elderly admissions and usually require longer treatment in healthcare facilities followed by rehabilitation and/or community care. Adhering to the Length Of Stay (LOS)-based cut-off point set by healthcare executives in Ireland, frail patients were characterized in this study as those who need a treatment period in acute system (i.e., hospitals) of more than 15 days: The remaining $80-82 \%$ of elderly patients (who receive shorter treatment periods) are referred to as non-frail.

The elderly patients come to acute hospitals from the surrounding community. There are two groups of patients: elective and emergency. This study has taken an attention in the emergency group. The journey of an elderly patient through the hospital usually begins with patient's arrival at the ED by ambulance or walk-in. The reasons that affect the pattern of patients' arrivals are outside the scope of this study; arrival rates of elderly patients are considered exogenous to the model. The rate of admission of new emergency patients is mainly controlled by the bed management team within hospitals. Lack of available acute beds may cause delays in ED admission, so incorporating the status of the beds in crucialbed occupancy (i.e. the ratio between all occupied beds and the total beds capacity). After admission, elderly patients receive treatment in an acute bed until they have assigned a care pathway subject to their diagnosis and frailty level. The duration of treatment ranges from few days to two weeks for non-frail patients, but usually may exceed this period especially for frail patients. The discharge rate influences acute hospital occupancy and is related to the LOS. Several factors are influencing LOS such as elderly patients' profile, quality of the service and availability of post-acute care capacity. Elderly patients' alternative care pathways and their required bed resources are illustrated in Table 1.

Table 1: Discharge Destinations Profile

\begin{tabular}{|l|c|c|c|}
\hline \multirow{2}{*}{ Discharge Destinations } & \multicolumn{3}{|c|}{ Percentage of Patients } \\
\cline { 2 - 4 } & Frail & Non-frail & All 65+ Patients \\
\hline Home & $24.2 \%$ & $78.4 \%$ & $68.6 \%$ \\
\hline Another Hospital & $08.2 \%$ & $05.7 \%$ & $06.1 \%$ \\
\hline Rehabilitation & $36.0 \%$ & $00.0 \%$ & $06.5 \%$ \\
\hline Convalescence & $00.0 \%$ & $10.5 \%$ & $08.6 \%$ \\
\hline Long Term Care & $19.5 \%$ & $00.0 \%$ & $03.5 \%$ \\
\hline Died & $10.8 \%$ & $04.3 \%$ & $06.1 \%$ \\
\hline Other & $01.3 \%$ & $01.1 \%$ & $01.1 \%$ \\
\hline
\end{tabular}

Accessing HSE nursing homes and community care may require waiting based on the bed capacity availability of the post-acute care services. Consequently, shortages in rehabilitation, convalescence, Long Term Care (LTC), and Home Care Packages (HCP) bed or service capacities are the main reasons behind delayed discharges from acute hospitals.

\subsection{Causal Loops/Dynamic Hypothesis}

The dynamics of the system can be caused by feedback loops. A causal loop diagram illustrates the main feedback loops of the key variables influencing the elderly care discharge pathways (Figure 1). There are two types of feedback loops: balancing loops (B) and reinforcement loops (R). Balancing loops (or selfcorrecting) counteract and oppose change. The balancing loops behave like goal seeking with implicit or explicit goals. All balancing loops are controlled with the bed capacity of either acute hospitals or postacute care. The admission loop (B1) is responsible for the emergency admission of elderly patient waiting 
in ED. As number of waiting patients in ED increases the admission rate increases as well subject to the availability of acute beds. This leads to an increase in bed occupancy levels until its maximum level is reached (B2). As a result, no more acute beds are available and acute admissions are prevented. The acute bed occupancy loop is therefore a main balancing loop because it controls the acute care admission process. Patients are ready to be discharged upon completing their treatment episode and when they are medically fit (i.e. the treatment loop (B3) represents the treatment process for patients in the acute hospitals). Patients who are medically fit and waiting for discharge assessment are still occupying acute beds, hence bed occupancy level remains unchanged (B4). Patients who require post-acute care (e.g. rehabilitation, convalescence, long-term care) and are waiting for this service, are still occupying acute beds which cause a bed blocking problem in the whole healthcare system (B5a). The loop that controls post-acute admission for elderly patients is the acute bed unblocking loop (B5b). This loop is an essential loop because it works as releaser for the blocked acute beds. Increasing the discharge rate from post-acute care decreases the post-acute bed occupancy and hence increases the admission to post-acute care that reduces the acute bed occupancy level.

The post-acute bed occupancy loop (B6) prevents any admission to post-acute care as long as there is no available bed. B7 loop controls the releasing of acute beds which are blocked by elderly patients who are waiting for post-acute services by increasing the admission rate to post-acute care. Discharging elderly patients form post-acute releases beds in post-acute care for new admissions (B7). As the discharge rate of post-acute care increases, the occupancy level of post-acute beds decreases as well and the admission rate to post-acute care increases.

Reinforcement loops (R1 - R4), on the other hand, tend to reinforce or amplify whatever is happening in the system. These loops are responsible for the discharge pathways from the acute hospitals. All of them are reinforcing loops because the more patients are discharged from hospitals, the more acute beds are available and hence the more new admission occur.

\section{STOCK AND FLOW MODEL}

A stock and flow diagram was developed to simplify the elderly care discharge pathways and to describe the flow of elderly patients through the different care pathways (Figure 2). The boxes represent stocks which is used to reflect the different states of care for patients. Elderly patients wait in stocks for further progress through the system. The flow of elderly patients is depicted by double lines which represent the flow of patients from one state to the other in the model. The cloud symbol represents out of scope source or destination. A valve symbol represents a rate that regulates a flow from a source to destination state.

\subsection{Data Calibration}

Historical admission and discharge data were collected from the central healthcare information system, while bed capacities and LOS data were gathered through national surveys. Besides, bed capacity figures for long term care were gathered from HSE long stay annual report (Department of Health 2010). As in other healthcare modeling projects, collecting the relevant modeling data presented considerable challenges (Roberts 2011). The main challenge was the dearth of data about certain parameters such as demand, admissions, current waiting times, delays and current LOS of certain services. It is worth noting that a similar project undertaken study elderly care in the UK had to alter its objective from producing quantitative results to only building a simulation model due to the lack of relevant data (Katsaliaki et al. 2005). Another challenge was related to the aggregate figures representing the elderly population service. For example, the number of patients discharged to multiple destinations was combined into a single number, while modeling inputs require such figures to be broken down into individual elements. The third problem with data in this case was inconsistencies between different data sources, such as variations in figures between hospitals data and annual reports. After numerous extended meetings with HSE officials, the absence of certain data and lack of information on how to decompose aggregated figures were overcome by the use of assumptions based on the opinions of experts in the field (Standridge 1999). 


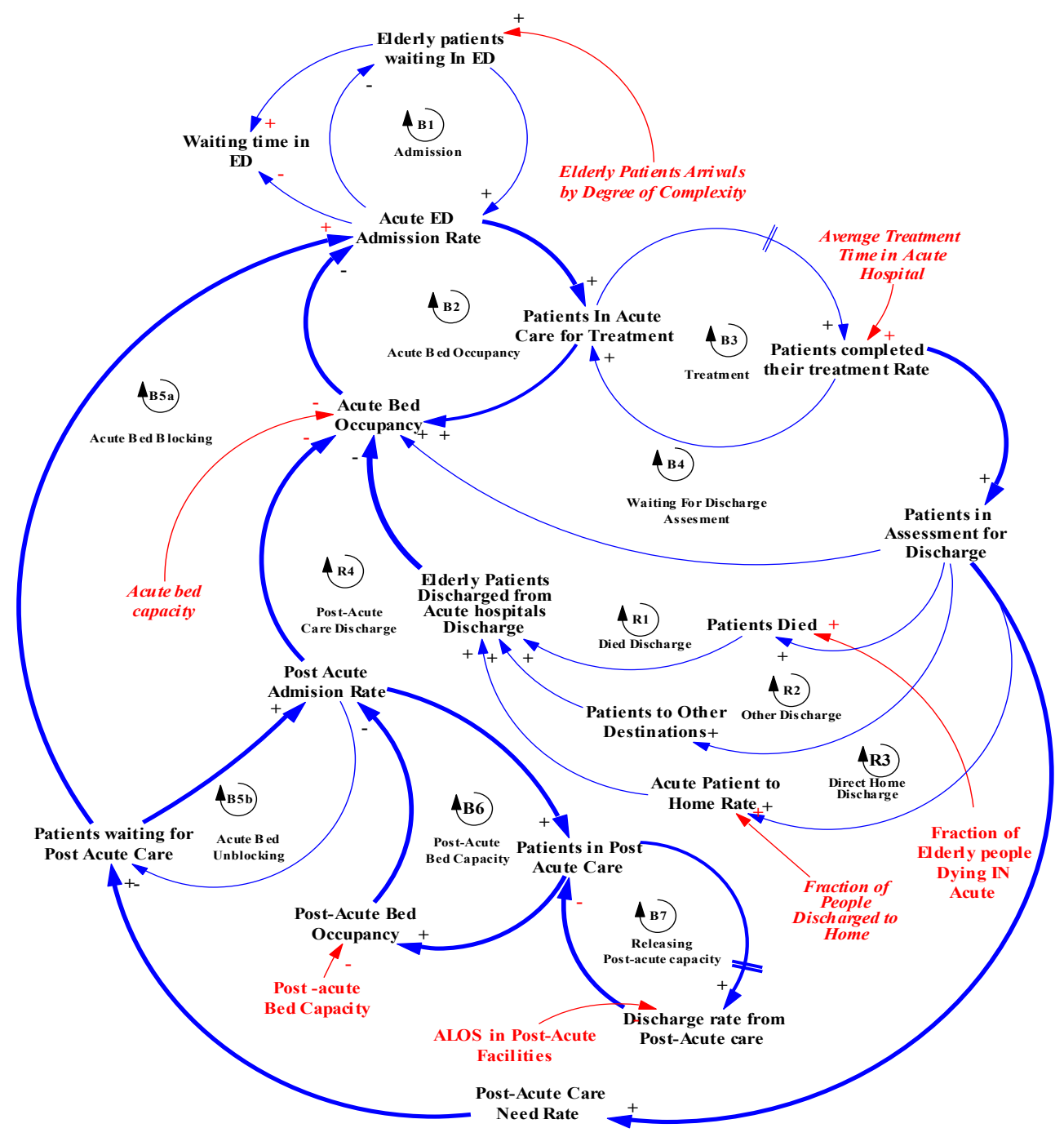

Figure 1: Causal Loop Diagram for Elderly Care Discharge Pathways

Data analysis was used to extrapolate important inputs for the model, such as arrival and discharge patterns (Figure 3). The distribution of the daily patients arrival is shown in Figure 3a. The total emergency admissions of elderly patient record was nearly 153,000 patients in 2010 . More than $75 \%$ of days was between 575 and 675 elderly patients, with an average daily arrival rate of 587 elderly patients and standard deviation 88.26 patients. Figure $3 \mathrm{~b}$ presents the monthly demand of patients as a percentage of the total annual demand, which shows the distribution of demand across the months is approximately uniform. However, patient arrival numbers for December were significantly lower than for other months, which may be due to demand decay during the Christmas holidays - demand returns to normal levels in January.

\subsection{Degree of Complexity}

Elderly patients differ according to their needs and the severity of those needs. Accordingly, it is essential to use different arrival patterns to reflect the characteristics and needs of different groups of patients. Data were clustered to group frail patients according to their acute LOS into two categories (Frail and Nonfrail), representing the degree of complexity (DOC) of their needs, based on the validated assumption that the most complex cases spend more time in hospitals. The majority of elderly patients (approx. 82\%) are classified as non-frail patients with no degree of complexity and $18 \%$ of elderly patients are classified as 
frail patients. Figure 4 shows the different sources of admission categorized by age group. About $90 \%$ of all elderly demand is sourced from home, and the figure shows that the demand percentage of patients coming from home has a negative slope as patients get older. This reflects the demand nature of increasing old people. For the age group 65-69 years, 93\% of patients come from home and 7\% of patients from other sources. This demand pattern changes as the patients get older; for $85+$ years age group, about $84 \%$ of patients come from home sourced and $16 \%$ from elsewhere. This emphasizes the fact that elderly people - in particular frail patients - need more care and treatment which they cannot be provided at home.

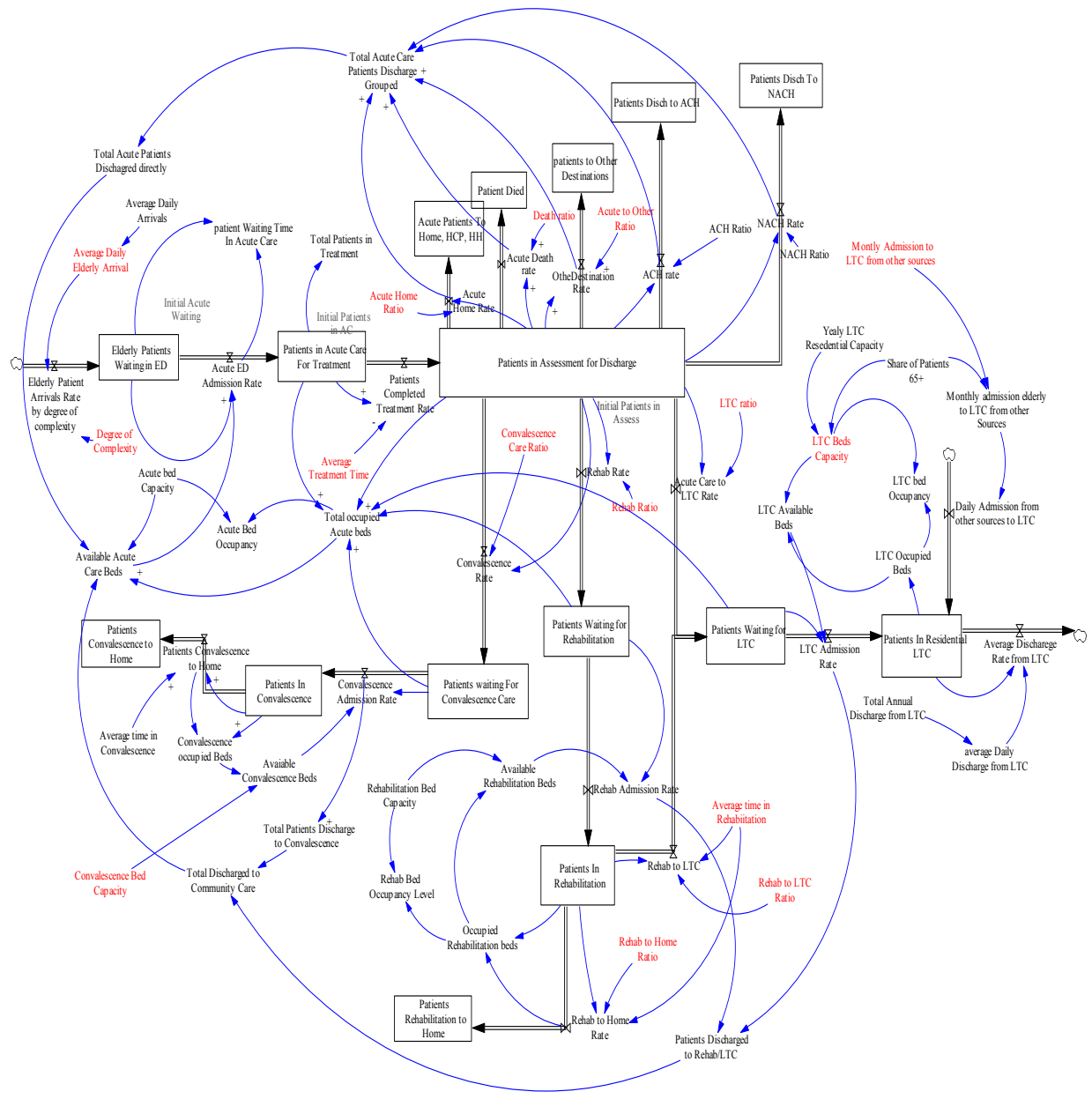

Figure 2: A Stock and Flow Map Representation for Elderly Care Discharge Pathways

\subsection{Model Validation}

To reduce the model development cycle time and to increase the confidence in the model results, verification and validation were carried out throughout the development phases of the project. Several model tests were applied on the model which mainly include structure and behavior tests. The model structure was discussed and verified by HSE officials and experts at different stages to ensure the consistency of the model with the real problem. Delayed discharge data (HSE 2012) was used for conducting the behavior validation test where the model output is compared with the actual reported national figures (Figure 5). Other tests have been performed such as extreme conditions test to ensure positive flows of patients and logical behavior of variables at extremes, model boundary and integration error (Sterman 2000). 


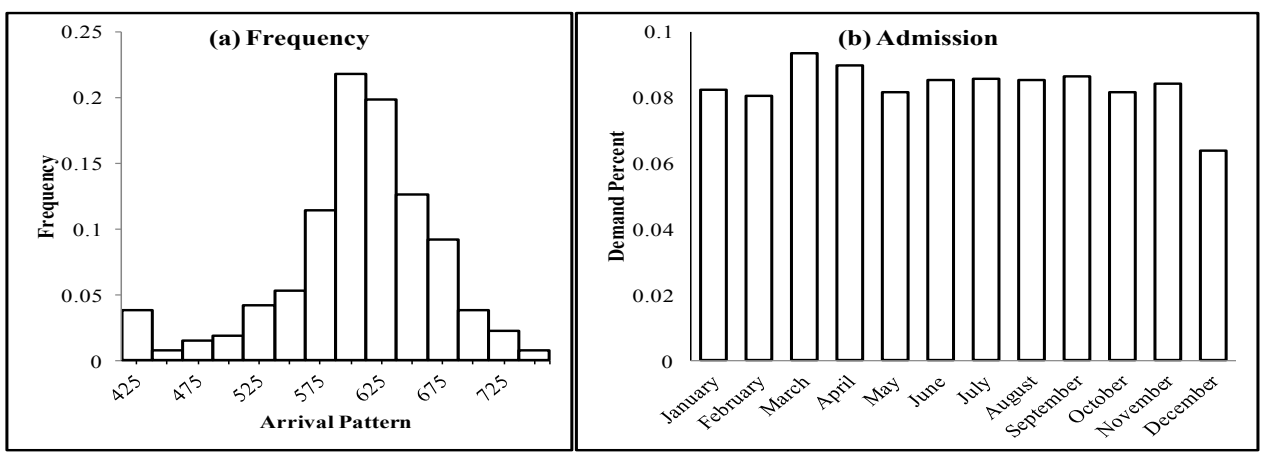

Figure 3: Arrival Pattern of Elderly patients in year 2010.

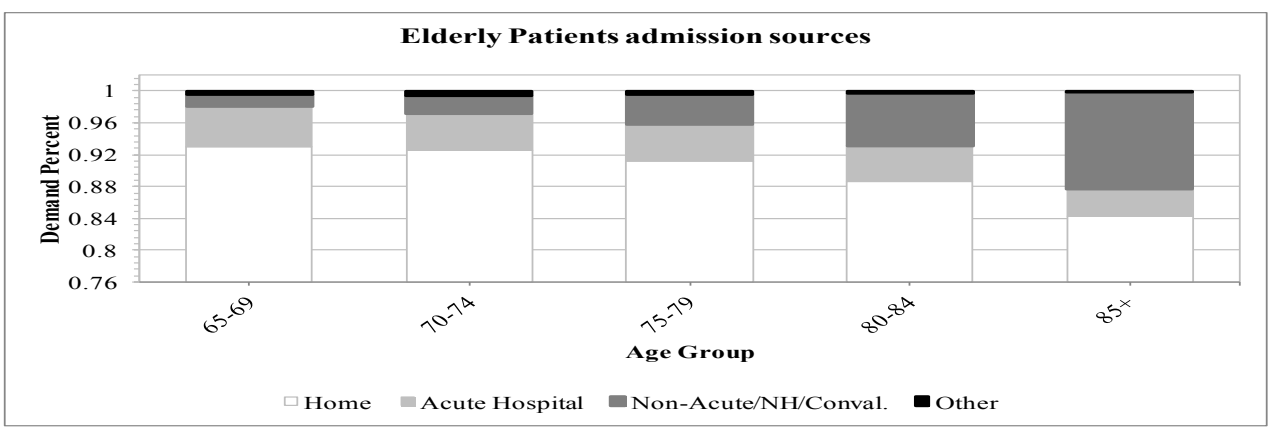

Figure 4: Elderly Patients Admission Sources.

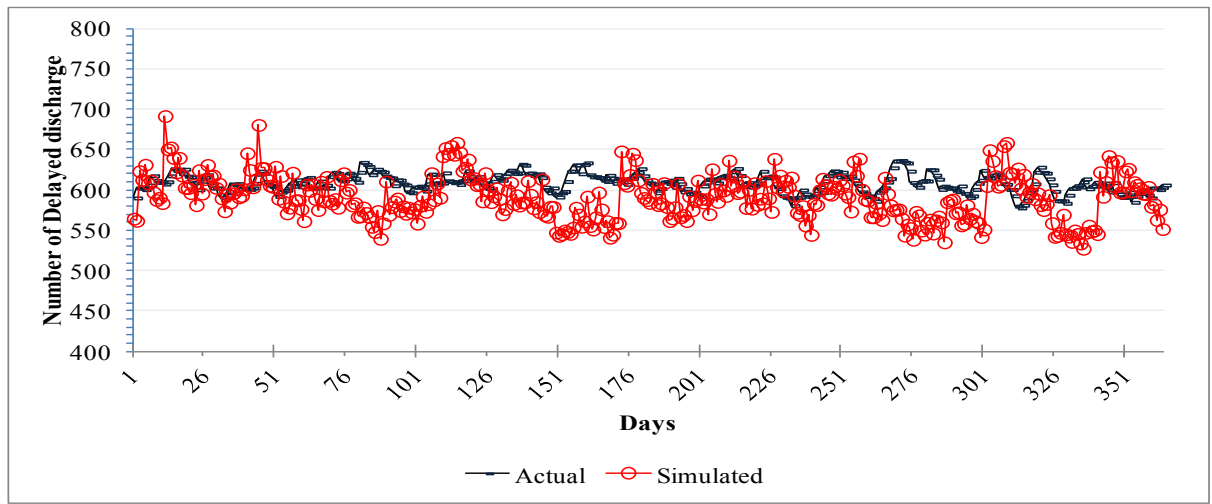

Figure 5: Model Validation using Number of delayed discharge.

\subsection{Policy Testing}

Ireland has a significant population growth, especially for aging people which is expected to reach $15.4 \%$ of the population by 2021 (Wren et al. 2012). Therefore, the care demand for elderly people will increase drastically. This growth will be of proportion to elderly aged 80 - usually defined as frail and require long term care in most cases. Accordingly it is imperative to consider the projected future elderly care demand when testing policies.

Due to the worsening economic outlook, substantial cuts in public healthcare expenditure are made. Number of acute bed closed from 2007 to 2011 is nearly 1,274 beds (The Economic and Social Research Institute 2011). These figures made the option of expanding acute care capacities infeasible policy intervention. Table 2 summarizes the policy interventions that were proposed by the HSE The results of the proposed polices against the base model is presented (Figure 6). Base model reflects the status without any policy interventions; hence the delayed discharge will continue to increase (Figure 6a). 
The impact of increasing long term bed capacity (i.e. policy 1) on delayed discharge is minimal and temporary. Initially numbers of delayed discharge decreased for a short period and then back to increase as time progresses. Increasing the accessibility of GPs to community services (i.e. policy 2) makes some improvement over a short period of time due to the reduction of the demand on the acute care. However the increase in demand depresses the impact of this policy over time. Similarly, policy 3 works to increase throughput of long term care facilities, but the demand for the long term care continue to increase rapidly compared to the discharges from long term care. Policy 4 failed to mitigate the delayed discharge, despite it is a mixture between policy 1 and 2. All the first four policies cannot cope with the increase in number of discharges for a short term and their impacts against the demand impact is little. In contrary, policy 5 shows more promising outcome than the other policies in reducing number of delayed discharge.

Table 2: Policies Description.

\begin{tabular}{l|l}
\hline Policy & \multicolumn{1}{c}{ Policy Description } \\
\hline Base & $\begin{array}{l}\text { A base run of the model taking into consideration the impact of the demographics changes } \\
\text { into elderly care demand pattern. The aim of this policy is to explore how the model, within } \\
\text { the current capacities, behaves with the continuing rises in demand. }\end{array}$ \\
\hline Policy 1 & $\begin{array}{l}\text { A post-acute policy by increasing the long term care, such as nursing homes, and } \\
\text { rehabilitation by 20\% (stock intervention). }\end{array}$ \\
\hline Policy 2 & $\begin{array}{l}\text { A pre-acute care flow policy intervention. This policy is to increase the accessibility of GPs } \\
\text { to community services in order to avoid unnecessary admissions to acute systems. This } \\
\text { policy is intended to reduce the need for hospitalization and mitigate the pressure on the } \\
\text { acute hospital resources. This policy is implemented in the model by 15\% decrease of } \\
\text { elderly acute emergency admissions. }\end{array}$ \\
\hline Policy 3 & $\begin{array}{l}\text { A post-acute flow policy intervention. This policy is concerned with the long term care } \\
\text { facilities such as nursing homes, where patients stay extended periods compared with acute } \\
\text { care. Increasing the discharge rate from long term care facilities by making improvements in } \\
\text { homecare packages, which is a preferred option for elderly people. A 10\% increase in the } \\
\text { out flow from long term care was proposed. }\end{array}$ \\
\hline Policy 4 & A combination policy between policy 1 and 2. \\
\hline Policy 5 & A combination among policy 1,2, and 3. \\
\hline
\end{tabular}

Figure $6 \mathrm{~b}$ shows the AVLOS against different policies. For various policies, the number of delayed discharge increases, the AVLOS of elderly frail patients has also increased (Figure 6b). All the first three policies failed to decrease the AVLOS of frail patients or to decrease the number of delayed discharge. Policy 4 decreased slightly the AVLOS, but in average it is still high and unacceptable. In contract, policy 5 is the most effective in decreasing the AVLOS in acute hospitals for elderly frail patients.

Figures $6 \mathrm{c}$ and $6 \mathrm{e}$ present the acute bed occupancy and percentage of blocked beds for the different policies. Policy 1 achieves high utilization of the acute care resources that reaches to $96 \%$ occupancy level, where about $16 \%$ of the total acute beds are blocked. Policy 2 mitigates the pressure on the acute care in the early time, but as soon as the demand is increasing, the acute occupancy rising until to reach the maximum occupancy; about $13 \%$ of the total acute beds are blocked. The acute bed occupancy for both policies 3 and 4 is continuing to increase. The occupancy level is about $76 \%$ on average for policy 5 , which is the minimum occupancy level among all policies, coupled with less than $1.7 \%$ of the total acute beds are blocked. Moreover, this policy achieved the highest accessibility for post-acute care (Figure 6d) which measures the proportion of patients who need post-acute care to patients who actually received this service, within a waiting period of two months or less. 

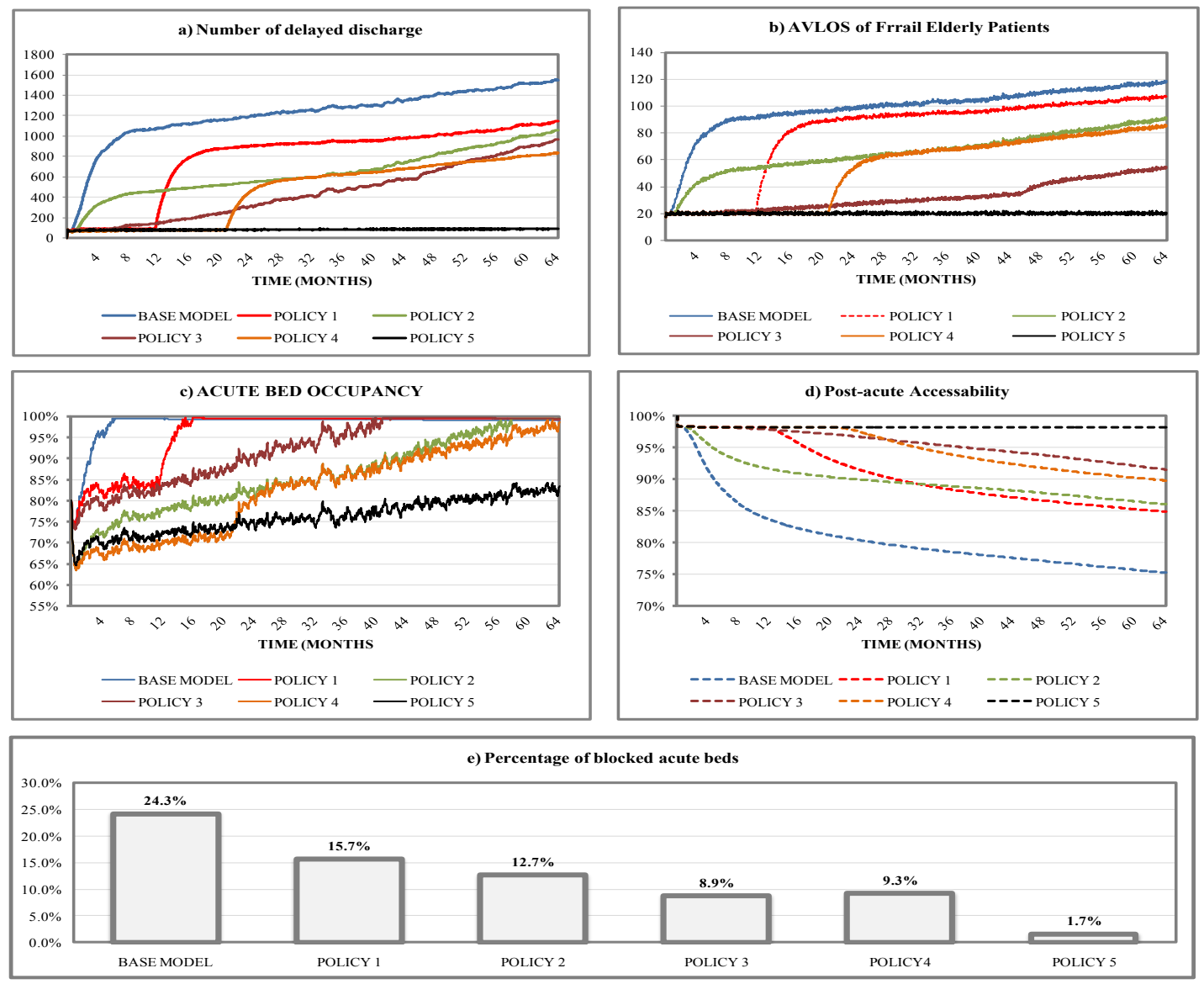

Figure 6: Results of policies testing

\section{DISCUSSION}

The results from base model revealed that there are on average about 600 delayed discharge monthly. More than $80 \%$ of them are due to long term care. Different reports stated that the average cost of running an acute bed is $€ 850$ per night and hence cost of caring 600 delayed patients is about $€ 510,000$ per day. Therefore reducing the number of delayed discharges will result in significant financial savings and hence these savings can be directed to improve community-based care services.

The results of the proposed policies indicated that the impact of increasing post-acute bed capacity is temporary and over-time is insignificant. When post-acute bed capacity increases, more patients will be admitted to, or receive, post-acute services, resulting in increasing the availability of acute beds. However, the impact of the capacity expansion is temporary, as soon as the additional capacity is utilized, the number of patients waiting for the services increases and a proportional increase of blocked acute beds. The response of this capacity expansion policy can be explained by loop B6 in figure 1 . This is the case of stock policy interventions which has a limited-time effect and may stimulate more demand.

The flow intervention policies can be influential to reduce the pressure on the acute care if it combines with the capacity expansion of post-acute care. A combination of the three policies, is more effective to improve performance than implementing each policy independently. Creating new pathways to reduce the emergency admissions and/or reducing length of stay in long term care can make significant improvement if the demand is stable. But, the rapid increase in demand requires mixture of stock and flow policy interventions (policy 5). Policy 5 achieved the lowest acute bed occupancy about $76 \%$ and a percent of blocked acute beds less than $1.7 \%$ of the total acute bed capacity. This gives opportunity to HSE executive to relief the financial pressures by closing some of acute beds and save a significant cost 
of delayed discharges, which may be used to improve healthcare service or increase the investment in the long term care which will mitigate the pressure in the acute care facilities. Increase the capacity of long term care can be achieved by encouraging private sector to invest - motivation using tax incentives might help. An evidence from best practice in other countries shows that acute and long-term care are substitutes. Studies of the factors of acute utilization in the UK have found that the availability of residential long-term care decreases acute care utilization (Department of Public Expenditure and Reform 2012).

\section{CONCLUSION}

The mounting demand of elderly healthcare services is driven by increasing population ageing. This is confronting Irish healthcare executives with critical capacity planning challenges. Developing a model to investigate the service constraints is found to be supportive to decision makers in their process to assess their policies. Conceptual modeling is used to illustrate different elderly patient care pathways and provides a better understanding of the resources required during the care journey. The developed system dynamics model enhanced the understanding of the dynamic complexity inherited in the system due to conflicting elements. This is achieved by enabling feedback structure of the problem using causal loop diagram of key variables. This phase followed by developing a stock and flow diagram to track patients' paths through the system.

The model is of a great benefit to policy makers especially when forecasting the outcomes of the proposed policies to overcome the delayed discharge for elderly patients. A combination of the stock interventions and flow interventions seems to be more effective than implementing each intervention independently. The impact of stock interventions, such as increasing post-acute capacity, is temporary and does not meet the expected future demand. On the other hand, flow intervention policies can be very effective to reduce the pressure on the acute care if it combines with the capacity expansion of post-acute care. Policy 5 (increasing the long term care capacity by $20 \%, 15 \%$ reduction of elderly acute emergency admissions, and $10 \%$ increase in the long term care discharge ) can reduce the acute bed occupancy significantly (about 76\% occupancy level) and also put down delayed discharge percentage (less than 1.7 $\%$ of total acute bed capacity). This enables HSE executive to cope with the financial pressures by closing some of acute beds resulting savings in cost of delayed discharges. This saving can be used to further improve the service provided or plan long term strategy that copes with the growth in demographical patterns. Next phase of the project will aim to address long term planning in non-acute service for local communities. It is anticipated that the challenges are; defining the catchment areas for each local community in terms of demographic characteristics, finding available community services and acute hospitals, and planning for the resources required.

\section{REFERENCES}

Abohamad, W. and A. Arisha. 2013. "Simulation-based Framework to Improve Patient Experience in an Emergency Department." European Journal of Operational Research 224:154-166.

Abo-Hamad,W., J. Crowe, and A. Arisha. 2012. "Towards Leaner Healthcare Facility: Application of Simulation Modelling and Value Stream Mapping" In Proceedings of the 9th International Multidisciplinary Modeling \& Simulation Multiconference (I3M), The International Workshop on Innovative Simulation for Healthcare (I-WISH), 19 - 21 September, Vienna, Austria.

Brailsford, S.C. 2008. "System Dynamics: What's in it for Healthcare Simulation Modelers." In Proceedings of the 2008 Winter Simulation Conference, Edited by S. J. Mason, R. R. Hill, L. Mönch, O. Rose, T. Jefferson, J. W. Fowler, 1478-1483, Piscataway, New Jersey: Institute of Electrical and Electronics Engineers, Inc.

Brailsford, S. C., and N. A. Hilton. 2001. "A comparison of discrete event simulation and system dynamics for modelling health care systems." Proceedings from ORAHS 2000, Glasgow, Scotland, ed. J. Riley, 2001, 18-39. 
Connell, P. and L. Pringle. 2004. "Population Ageing in Ireland." Dublin, National Council on Ageing and Older People. http://www.nuim.ie/staff/dpringle/ncaop-report.pdf.

Department of Health. 2010. "Long-Stay Activity Statistics." Annual report. http://www.dohc.ie/publications/pdf/long_stay_2010.pdf.

Department of Public Expenditure and Reform. 2012. Databank http://per.gov.ie/databank/ [accessed 12 November 2012].

Desai, M.S., M.L. Penn, S.C. Brailsford, and M. Chipulu. 2008. "Modelling of Hampshire Adult Services gearing up for future demands." Health Care Management Science 11:167-176.

Eldabi, T., R. Paul, and T. Young. 2006. "Simulation modelling in healthcare: reviewing legacies and investigating futures." Journal of the Operational Research Society 58:262-270.

EVETOVITS, T. 2012. "Health system responses to financial pressures in Ireland: policy options in an international context." Technical report. http://www.dohc.ie/publications/pdf/Observatory_WHO_2012.pdf.

HSE. 2012. "Delayed Discharge National Report", Dublin: Department of Health. accessed March 15 2013. http://www.oireachtas.ie/parliament/media/committees/pac/correspondence/2012meeting512009/ [PAC-R-593] Correspondence-3A.7.pdf

Katsaliaki, K., S. Brailsford, D. Browning, and P. Knight. 2005. "Mapping care pathways for the elderly." Journal of Health Organisation and Management 19:57-72.

Liotta, G., S. Mancinelli, P. Scarcella, and L. Gialloreti. 2011. "Determinants of acute hospital care use by elderly patients in Italy from 1996 to 2006." Archives of gerontology and geriatrics 54:364-369."

Litvak, N., Van Rijsbergen, M., Boucherie, R.J., and M. Van Houdenhoven. 2008. "Managing the overflow of intensive care patients." European Journal of Operational Research 185:998-1010.

Majeed, M., D. Williams, R. Pollock, F. Amir, M. Liam, K. Foong, and C. Whitaker. 2012. "Delay in discharge and its impact on unnecessary hospital bed occupancy." BMC Health Services Research 12:410-416.

Mcdermid, R. C. and S. M. Bagshaw. 2011. "ICU and critical care outreach for the elderly Best practice \& research." Clinical anaesthesiology 25:439-49.

$\mathrm{Ng}$, A., C. Sy, and J. Li. 2011. "A system dynamics model of Singapore healthcare affordability." In Proceedings of the 2011 Winter Simulation Conference, Edited by S. Jain, R.R. Creasey, J. Himmelspach, K.P. White, and M. Fu, 1-13, Piscataway, New Jersey: Institute of Electrical and Electronics Engineers, Inc.

Paul, J. A. and G. Hariharan. 2007. "Hospital capacity planning for efficient disaster mitigation during a bioterrorist attack." In Proceedings of the 2007 Winter simulation conference, Edited by S. G. Henderson, B. Biller, M.-H. Hsieh, J. Shortle, J. D. Tew, and R. R. Barton, 1139-1147, Piscataway, New Jersey: Institute of Electrical and Electronics Engineers, Inc.

Piers, R. D., I. J. Van Eechoud, S. Van Camp, M. Grypdonck, M. Deveugele, N. C. Verbeke, And N. J. Van Den Noortgate. 2011. "Advance Care Planning in terminally ill and frail older persons." Patient Education and Counseling 90:323-329.

Ragab, M., W. Abo-Hamad, and A. Arisha. 2012. "Capacity Planning for Elderly Care in Ireland Using Simulation Modeling." In Proceedings of the fourth International Conference on Advances in System Simulation, Lisbon, Portugal, 18th-23rd November, 2012.

Tandridge, C. R. 1999. "A tutorial on simulation in health care: applications issues." In Proceedings of the 1999 Winter Simulation Conference, Edited by P. A. Farrington, H. B. Nembhurd, D. T. Sturrock, and G. W. Evansa, 49-55, Piscataway, New Jersey: Institute of Electrical and Electronics Engineers, Inc.

Sterman, J. 2000. Business Dynamics: System Thinking and Modeling for a Complex World. Boston:Irwin/McGraw Hill.

The Economic and Social Research Institute. 2011. "Activity In Acute Public Hospitals In Ireland." Annual Report. http://www.esri.ie/_uuid/462574ea-80a8-4bb4-96ea-31bf0fdcfc2d/2011-HIPEAnnual-Report-Final.pdf 
Thorwarth, M., A. Arisha, P. Harper. 2009. "Simulation model to investigate flexible workload management for healthcare and servicescape environment." In Proceedings of the 2009 Winter Simulation Conference, Edited by Rossetti, M.D., Hill, R.R., Johansson, B., Dunkin, A., Ingalls, R.G, 1946-1956, Piscataway, New Jersey: Institute of Electrical and Electronics Engineers, Inc.

Walker, B. C. and T. Haslett. 1999. "System dynamics and action research in aged care." Australian Health Review 24:183-191.

WHO. 2011. "10 facts on ageing and the life course." http://www.who.int/features/factfiles/ageing/en/index.html [Accessed March 2012].

Wolstenholme, E.F. 1993. "A case study in community care using systems thinking". Journal of the Operational Research Society 44:925-934."

Wolstenholme, E.F. 1999. "A patient flow perspective of U.K. Health Services: Exploring the case for new intermediate care initiatives." System Dynamics Review 15:253-271.

World Health Organization. 2012. " Health system responses to financial pressures in Ireland: policy options in an international context". http://www.dohc.ie/publications/pdf/Observatory_WHO_2012.pdf [Accessed April 2013].

Wren, M., C. Normand, D. O'Reilly, S. Cruise, S. Connolly, C. Murphy. 2012. "Towards the Development of a Predictive Model of Long-Term Care Demand For Northern Ireland and the Republic of Ireland." Dublin: Centre for Health Policy and Management, Trinity College Dublin. Available: http://www.medicine.tcd.ie/health_policy_management [accessed March 2013].

Xiao, N., R. Sharman, H. R.Rao, \& S. Dutta. 2012. "A simulation based study for managing hospital emergency department's capacity in extreme events." International Journal of Business Excellence 5:140-154.

\section{AUTHOR BIOGRAPHIES}

WAEL RASHWAN, MSc. is a researcher in 3S Group (A research unit in College of Business - Dublin Institute of Technology (DIT) specialized in complex systems simulation and optimization). He joined the 3S in 2013. He has a B.Sc. and M.Sc. degree in operations research form Cairo University. Wael has extensive experience in Industry. His research interests include: Modeling and simulation, Optimization, Game Theory and Probability Collectives. His email address is <wael.rashwan@mydit.ie>.

MOHAMED AF RAGAB, MBA is a Part-Time researcher in 3S Group and also the Secretary General of Pharos University in Alexandria (PUA). He received his B.Sc. degree in Industrial Engineering and his MBA from the American University in Cairo (AUC). Mohamed is at his final stages to complete his PhD at College of Business - DIT. His research interests include; Knowledge Management and Simulation Modeling. His email address is $<$ mohamed.ragab@mydit.ie $>$.

WALEED ABO-HAMAD, Ph.D. is a senior researcher in $3 \mathrm{~S}$ Group and Lecturer in School of Management (DIT). He joined the 3S group in 2008 having spent four years as a researcher in Cairo University where he received his B.Sc. and M.Sc. degrees in Computer Science. He received his Ph.D in service process optimization from DIT. His research interests include Modeling and Simulation, Optimization, Computational Intelligence, Machine Learning and Cooperative Intelligent Systems. His email address is <waleed.abohamad@dit.ie>.

AMR ARISHA, Ph.D. is the director of the 3S Group and the head of international business department in college of business in Dublin Institute of Technology. He Joined DIT in 2005, he received his PhD in Industrial Engineering from Dublin City University (DCU). Intel-Ireland has sponsored his research from 2000 - 2005. His research interests include analysis and optimization of complex dynamic systems in manufacturing and service industries. He is a member in IIE, IMECH, IEI, ESE, ORS, IEEE and ASME and Chief Examiner at MII. His e-mail address is<amr.arisha@dit.ie>. 